\title{
DIOXIN AND PCB LEVELS IN BLOOD AND HUMAN MILK IN RELATION TO LIVING AREAS IN
} THE NETHERLANDS.

C. Koopman-Esseboom ${ }^{1}$, M. Huisman ${ }^{2}$, N. Weisglas-Kuperus ${ }^{1}$, E.R. Boersma ${ }^{2}$, M.A.J. de Ridder ${ }^{3}$, C.G. Van der Paauw ${ }^{4}$, L.G.M.Th. Tuinstra ${ }^{5}$, P.J.J. Sauer' ${ }^{1}$.

1 Department of Paediatrics, Division of Neonatology, Erasmus University and University Hospital/Sophia Children's Hospital, dr. Molewaterplein 60, 3015 GJ Rotterdam, the Netherlands.

2 Department of Obstetrics and Gynaecology, University of Groningen, the Netherlands.

3 Institute of Epidemiology and Biostatistics, Erasmus University Rotterdam, the Netherlands.

4 TNO Nutrition and Food Research, Zeist, the Netherlands.

5 DLO State Institute for Quality Control of Agricultural Products, RIKILT-DLO, Wageningen, the Netherlands.

Keywords: dioxins, PCBs, women, living area.

\begin{abstract}
Dioxins and polychlorinated biphenyls (PCBs) are ubiquitous toxic compounds in the environment. Negative influences of these compounds on the health status of human beings have been described. Especially susceptible might be the fetus, which is exposed in utero, and the newborn breast-fed infant, since both are exposed to relatively high levels of dioxins and PCBs during a critical period of organ growth and development.

We investigated PCB levels in 406 maternal plasma samples as well as PCB and dioxin levels in 172 human milk samples with relation to living area of women living for at least five years in the western industrialized part of the Netherlands or the northern more rural part. The western part was further subdivided into one urban and two highly industrialized areas.

After correction for covariates, we found significantly higher levels of PCB 118 in maternal plasma as well as significantly higher levels of the dioxin-TEQ and of ten individual dioxin and PCB congener levels in human milk in the western more industrialized areas of the Netherlands compared to the northern more rural part. We did not find significant differences in planar, mono-ortho or di-ortho PCB-TEQ levels in human milk between all different areas.

We conclude that significantly higher levels of a number of dioxin and PCB congeners are found in women living in industrialized areas compared to women living in rural areas in the Netherlands.
\end{abstract}

\section{Introduction}

Dioxins (polychlorinated dibenzo-p-dioxins (PCDDs) and dibenzofurans (PCDFs)), are formed as unwanted byproducts mainly during the production of chlorinated chemicals and during the combustion of municipal and hazardous waste. ${ }^{1,2}$ After an explosion in a herbicide factory in Seveso, Italy, a large amount of 2,3,7,8-TCDD, 
the most toxic dioxin congener, was released, and high levels (up to 56,000 ppt) could be measured afterwards in the blood of people living close to that factory. ${ }^{3}$ Elevated levels have also been detected in Vietnam veterans, who sprayed Agent Orange, a defoliant contaminated with dioxins during the production process. ${ }^{4}$ In the Netherlands elevated dioxin levels ( $>6 \mathrm{pg} \mathrm{TEQ} / \mathrm{g}$ fat) have been detected in the milk of cows, grazing close to waste incinerators. ${ }^{5}$

Polychlorinated biphenyls (PCBs) are commercial chemical mixtures produced on a large scale since 1930 because of their wide range of application in industry, ${ }^{6}$ such as coolant fluids in transformers and dielectric fluids in capacitors. Elevated levels could be measured in blood of transformer repair workers' ${ }^{7}$ and in blood of humans exposed accidentally to high levels of PCBs and PCDFs in rice bran oil for consumption. ${ }^{8}$ When their widespread occurrence in the environment and subsequent adverse health effects became clear, PCB production and use were banned in the late 1970s. However, humans are still exposed through PCB leakage of old capacitors and transformers and disposal of contaminated materials such as old paints and fire retardants. Otherwise large amounts of PCBs were dumped on land and in water and became widespread in the environment by long-range atmospheric transport.

The higher chlorinated congeners are chemically stable, highly lipophilic substances which accumulate in the food chain. Food, such as dairy products, meat and fish, is regarded to be the main source of background exposure for humans. ${ }^{9}$ Inhaling and dermal absorption could be additional sources of exposure to dioxins and PCBs.

It is well known that differences in human dioxin and PCB levels exist between countries. ${ }^{10}$ In this paper we wish to answer the question if differences exist, within a small country as the Netherlands, between heavily industrialized areas and more rural areas, assuming that food habits are not different.

\section{Methods}

The study group consisted of 418 healthy women recruited between June 1990 and June 1992 . Women were asked by their obstetrician or midwife to volunteer for the study. During the last month of pregnancy, mothers were visited at home for an explanation of the study protocol. The obstetric optimality scale ${ }^{11}$ was used to evaluate pregnancy and delivery. As far as smoking is concerned the women were categorized into 3 subgroups: nonsmokers, 1 to 10 cigarettes a day, or more than 10 cigarettes a day. Additional questions were asked about the living area from birth until the time of the study and about the duration of breast-feeding periods of older children. Pregnancy and delivery had to be passed without overt signs of serious illness or complications. All infants were born between the 37 th and 42 th weeks of pregnancy. All women were of the Caucasian race. Nobody was likely to be exposed to elevated levels of dioxins or PCBs during occupation.

One hundred and ninety-eight women who have been living for at least five years in Rotterdam city and the surrounding industrialized region in the western part of the Netherlands were selected for this study. Nine mothers in this region had been living in different living areas in the Netherlands or abroad during the last five years and were therefore excluded from this part of the study. The other 211 selected women were living in Groningen and the surrounding area, which is a semi-urban and rural region in the northern part of the Netherlands (see map, figure 1). 


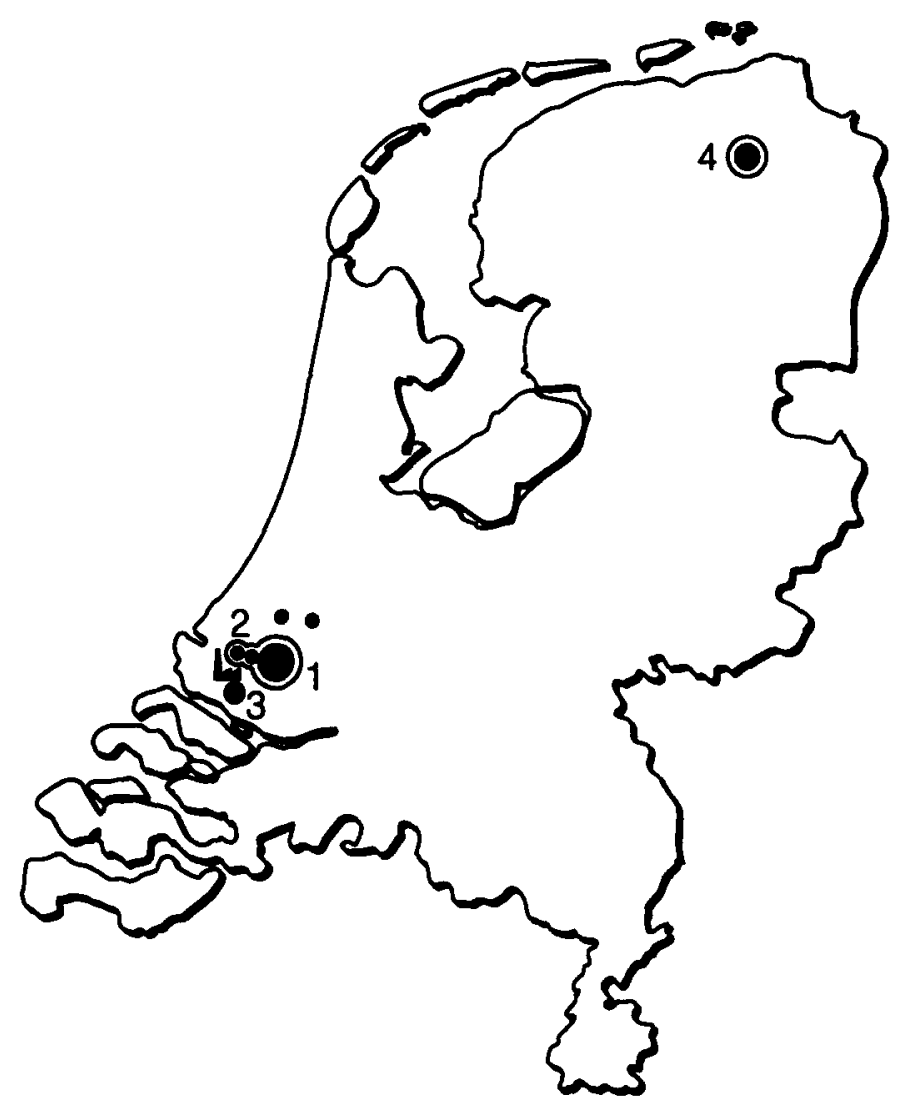

Figure 1 Map of the Netherlands.

1 =Rotterdam, 2 = Vlaardingen/Schiedam, 3=Spijkenisse, 4=Groningen. 
The group of 198 women living in the western part of the Netherlands was subdivided into three subgroups. One hundred and nine women were living in Rotterdam (map $\mathrm{nr} 1$ ), which is an urban area; 49 women lived in Vlaardingen or Schiedam (map nr 2) which is located on the northern edge of a highly industrialized zone containing a large waste incinerator and a number of large oil refineries and chemical industries; 40 women lived in Spijkenisse (map $\mathrm{nr}$ ) which is located on the southern edge of the same industrialized zone. The distance between the industrialized area and the living area is less than 6 kilometers and for some women it was less than 2 kilometers.

Of the group of 409 women, 202 breast-fed their infants. Fifty-two were living in Rotterdam, 30 in Vlaardingen or Schiedam, 17 in Spijkenisse and 103 in Groningen (map nr 4).

A blood sample was taken from the women in the last month of their pregnancy (36th to 40th week) for the measurement of the PCB congeners 2,3',4,4',5-pentachlorobiphenyl (PCB 118), 2,2', 3,4,4', 5' -hexachlorobiphenyl (PCB 138), 2, 2', 4, $4^{\prime}, 5,5^{\prime}$-hexachlorobiphenyl (PCB 153) and 2, ', $, 3,4,4^{\prime}, 5,5^{\prime}$-heptachlorobiphenyl (PCB 180)..$^{2}$ Blood was collected in a vacuum system EDTA-tube, transported in a cooling-pail, and within 24 hours centrifuged for 15 minutes at 3000 rates per minute; plasma was stored at $-20^{\circ} \mathrm{C}$ until analysis.

In the second week after delivery, the women who breast-fed their infants collected a 24-hour representative sample of breastmilk by collecting before each feeding as much milk as possible from both breasts with a vacuum pump. An aliquot of ten percent of each sample was pooled and stored in the refrigerator, the remainder was given to the infants in a bottle. After 24 hours the milk was stored at $-20{ }^{\circ} \mathrm{C}$ until analysis.

PCB congeners in plasma were measured by gas chromatography with electron capture detection (GC-ECD). ${ }^{13}$ The detection limit was $0.01 \mathrm{ng} / \mathrm{g}$ plasma.

The human milk samples were analyzed for the 17 most abundant 2,3,7,8-substituted PCDD and PCDF congeners and three planar PCB congeners (3,3',4,4'-tetrachlorobiphenyl (PCB 77), 3, 3', 4, ,',5-pentachlorobiphenyl (PCB 126), and 3,3',4,4',5,5'-hexachlorobiphenyl (PCB 169)) by gas chromatography-high-resolution mass spectrometry (GC-HRMS). ${ }^{14}$ Twenty-three non-planar PCB congeners (IUPAC no. 28, 52, 66, 70, 99, 101, 105, 118, 128, $137,138,141,151,153,156,170,177,180,183,187,194,195$ and 202$)^{12}$ were measured by gas chromatography with GC-ECD. ${ }^{15}$

To express the toxic potency of the mixture of dioxins and PCBs in breastmilk samples, the international toxic equivalence factor (I-TEF) approach ${ }^{16}$ was used for the PCDDs and PCDFs and the WHO 1993 approach for the PCBs. ${ }^{17}$ A TEF value was assigned to the dioxin and dioxin-like PCB congeners which represents their relative toxic potency compared to 2,3,7,8-TCDD, the most toxic dioxin congener which is assigned a TEF value of one. By multiplying the concentration (pg/g milkfat) and TEF value, the toxic equivalent (TEQ) of each congener was calculated (pg TEQ/g milkfat). By adding up the TEQs for all congeners the total-TEQ value was obtained. The TEQ-sum of the 17 dioxin congeners yielded a dioxin-TEQ, the three planar PCB $(77,126,169)$, three monoortho PCB $(105,118,156)$ and two di-ortho PCB congeners $(170,180)$ gave a planar, mono-ortho and di-ortho PCB-TEQ respectively. The other PCB congeners did not receive a TEF value because they have negligible dioxin-like activity.

The study protocol had been approved by the medical ethical committee of the University Hospital 
Rotterdam/Sophia Children's Hospital and the University of Groningen. Informed consent had been given by the parents.

Data analysis was performed by means of the statistical soft-ware package SPSS/PC. Means, $95 \%$ confidence intervals, ranges and standard deviations are reported in terms of original distributions.

Multiple regression analysis was used to test the influences of different covariates, which are well-known from the literature, on the dioxin and PCB levels. The four living areas as well as the three categories of smoking were entered in the regression analysis as dummy variables. Age in years, Quetelet index (weight/length' ${ }^{2}$ ) of the women before pregnancy, number of children delivered, weeks of breast-feeding to older children, fat percentage of the human milk sample and birthweight of the delivered infant were entered as continuous covariables. To correct for non-linear relationships, age and weeks of breast-feeding were also raised to a square and entered in the analyses. The PCB and dioxin levels were transformed by natural logarithmics if necessary.

\section{Results}

In table I the mean, standard deviation, 95\% confidence interval and range of the four PCB congener levels measured in maternal plasma are demonstrated for the four subgroups. One plasma sample in the Rotterdam group and two in the Groningen group were not determined. Oneway analysis of variance showed a significant difference in the PCB 118 level of women living in the different areas.

In table II the results of the dioxin, planar-, mono-ortho- and di-ortho-PCB TEQ levels, measured in human milk, are presented for the four subgroups. Due to analytical problems not all TEQ values could be calculated in the human milk samples, therefore the number of samples analysed in the four subgroups differ. There were no significant differences for these levels in the four living areas with the oneway analysis of variance test.

In table III demographic data of the four subgroups are presented, which are used as covariates in the multiple regression analysis. Oneway analysis of variance showed a significant difference in the covariates birthweight of the infants $(p=0.04)$ and age of the women $(p=0.002)$ within the breast-feeding groups of the different areas. For the other covariates there was no significant difference.

Multiple regression analysis was performed for all individual PCB and dioxin congener levels in plasma or human milk and for the TEQ levels in human milk. In table IV results are given for the PCB 118 level in plasma and the dioxin-TEQ level in milk. Both levels are significantly higher in Rotterdam and Spijkenisse compared to Groningen. Analysis of the individual congener levels in human milk showed that $1,2,3,4,7,8-\mathrm{HxCDD}$ (D66), 1,2,3,6,7,8-HxCDD (D67), 2,3,7,8-TCDF (F83), 1,2,3,4,7,8-HxCDF (F118), 1,2,3,6,7,8-HxCDF (F121), 2,3,4,6,7,8-HxCDF (F130) and 2,3',4,4'-tetrachlorobiphenyl (PCB 66), 2,2',3,4,4',5-hexachlorobiphenyl (PCB 137) and 2,2',3,4',5,5',6-heptachlorobiphenyl (PCB 187) were also significantly higher in the western areas compared to the northern area. The PCB 118 level in maternal plasma was also higher in Spijkenisse compared to Vlaardingen/Schiedam. There was no statistical significant difference in the planar, mono-ortho, di-ortho PCBTEQ levels or other individual congener levels for the different areas. 

PCB levels in maternal plasma (ng/g plasma).

\begin{tabular}{lccccc}
\hline & Rotterdam & $\begin{array}{c}\text { Vlaardingen/ } \\
\text { Schiedam }\end{array}$ & Spijkenisse & Groningen & P \\
& & $\mathrm{n}=108$ & $\mathrm{n}=40$ & $\mathrm{n}=209$ & \\
\cline { 2 - 7 } PCB 118 & & & & & \\
mean & $0.17 \pm 0.07$ & $0.16 \pm 0.08$ & $0.20 \pm 0.12$ & $0.15 \pm 0.08$ & \\
95\% c.i. & $0.16-0.18$ & $0.14-0.18$ & $0.16-0.24$ & $0.14-0.17$ & \\
range & $0.06-0.38$ & $0.02-0.39$ & $0.06-0.60$ & $0.04-0.58$ & .03 \\
PCB 138 & & & & & \\
mean & $0.58 \pm 0.24$ & $0.58 \pm 0.25$ & $0.66 \pm 0.31$ & $0.60 \pm 0.25$ & \\
95\% c.i. & $0.54-0.63$ & $0.51-0.65$ & $0.57-0.76$ & $0.56-0.63$ & \\
range & $0.16-1.40$ & $0.19-1.40$ & $0.30-1.50$ & $0.13-1.60$ & .43 \\
PCB 153 & & & & & \\
mean & $0.90 \pm 0.38$ & $0.88 \pm 0.36$ & $0.99 \pm 0.44$ & $0.89 \pm 0.36$ & \\
95\% c.i. & $0.83-0.98$ & $0.77-0.98$ & $0.85-1.13$ & $0.84-0.94$ & \\
range & $0.24-2.20$ & $0.29-1.90$ & $0.44-2.00$ & $0.18-2.30$ & .55 \\
PCB 180 & & & & & \\
mean & $0.53 \pm 0.24$ & $0.50 \pm 0.19$ & $0.58 \pm 0.25$ & $0.53 \pm 0.22$ & \\
95\% c.i. & $0.48-0.57$ & $0.45-0.56$ & $0.50-0.66$ & $0.50-0.56$ & \\
range & $0.13-1.30$ & $0.18-1.10$ & $0.25-1.20$ & $0.08-1.30$ & .50 \\
\hline & & & & & \\
\hline
\end{tabular}

$95 \%$ c.i. $=95 \%$ confidence interval $\mathrm{P}^{*}=$ overall $\mathrm{p}$-value, oneway analysis of variance on logarithmic scale. 
Table I Mean, standard deviation, 95\% confidence interval and ranges of dioxin and PCB levels in human milk (pg TEQ/g fat).

\begin{tabular}{|c|c|c|c|c|c|}
\hline & Rotterdam & $\begin{array}{l}\text { Vlaardingen/ } \\
\text { Schiedam }\end{array}$ & Spijkenisse & Groningen & $\mathbf{P}$ \\
\hline Dioxin-TEQ & $n=38$ & $\mathrm{n}=26$ & $\mathrm{n}=15$ & $\mathrm{n}=93$ & \\
\hline mean & $30.8 \pm 9.3$ & $30.3 \pm 13.2$ & $34.3 \pm 12.1$ & $28.9 \pm 9.7$ & \\
\hline $95 \%$ c.i. & $27.7-33.9$ & $25.0-35.6$ & $27.6-41.0$ & 26.9-30.9 & \\
\hline range & $11.1-56.5$ & $13.8-76.4$ & $15.8-56.7$ & $12.2-58.6$ & .34 \\
\hline $\begin{array}{l}\text { Planar PCB } \\
\text { TEQ }\end{array}$ & $n=44$ & $\mathrm{n}=30$ & $n=16$ & $n=99$ & \\
\hline mean & $16.4 \pm 5.9$ & $15.2 \pm 8.3$ & $18.0 \pm 9.7$ & $15.8 \pm 7.6$ & \\
\hline 95\% c.i. & $14.6-18.2$ & $12.1-18.3$ & $12.9-23.2$ & $14.3-17.3$ & \\
\hline range & $7.5-37.6$ & 4.4-35.9 & $7.9-45.7$ & $4.6-39.8$ & .38 \\
\hline $\begin{array}{l}\text { Mono-ortho } \\
\text { PCB TEQ }\end{array}$ & $n=49$ & $\mathrm{n}=30$ & $n=14$ & $\mathrm{n}=95$ & \\
\hline mean & $13.7 \pm 4.4$ & $14.1 \pm 5.9$ & $15.0 \pm 5.5$ & $15.5 \pm 5.5$ & \\
\hline $95 \%$ c.i. & $12.5-15.0$ & $11.9-16.3$ & $11.8-18.2$ & $14.4-16.6$ & \\
\hline range & $3.2-25.4$ & $6.4-24.0$ & $7.0-25.8$ & 5.9-30.4 & .23 \\
\hline $\begin{array}{l}\text { Di-ortho PCB } \\
\text { TEQ }\end{array}$ & $\mathrm{n}=49$ & $\mathrm{n}=30$ & $\mathrm{n}=14$ & $\mathrm{n}=95$ & \\
\hline mean & $4.0 \pm 1.4$ & $4.0 \pm 1.6$ & $4.3 \pm 1.8$ & $4.6 \pm 1.7$ & \\
\hline $95 \%$ c.i. & $3.6-4.4$ & $3.4-4.6$ & $3.2-5.3$ & $4.3-5.0$ & \\
\hline range & $1.6-9.7$ & $1.8-7.0$ & $2.2-8.3$ & $1.5-10.4$ & .15 \\
\hline
\end{tabular}

$95 \%$ c.i. $=95 \%$ confidence interval

$\mathrm{P}^{*}=\mathrm{p}$-value, oneway analysis of variance on logarithmic scale. 
Table III Means and standard deviation of the covariates in the four living areas.

\begin{tabular}{|c|c|c|c|c|c|c|c|c|}
\hline & \multicolumn{2}{|c|}{ Rotterdam } & \multicolumn{2}{|c|}{$\begin{array}{l}\text { Vlaardingen/ } \\
\text { Schiedam }\end{array}$} & \multicolumn{2}{|c|}{ Spijkenisse } & \multicolumn{2}{|c|}{ Groningen } \\
\hline & $\begin{array}{l}\text { blood } \\
n=108\end{array}$ & $\begin{array}{c}\text { milk } \\
\mathrm{n}=38\end{array}$ & $\begin{array}{l}\text { blood } \\
n=49\end{array}$ & $\begin{array}{c}\text { milk } \\
n=26\end{array}$ & $\begin{array}{l}\text { blood } \\
n=40\end{array}$ & $\begin{array}{l}\text { milk } \\
n=15\end{array}$ & $\begin{array}{l}\text { blood } \\
n=209\end{array}$ & $\begin{array}{c}\text { milk } \\
\mathrm{n}=93\end{array}$ \\
\hline age & $\begin{array}{c}28.8 \pm \\
4.0\end{array}$ & $\begin{array}{c}28.2 \pm \\
3.2\end{array}$ & $\begin{array}{c}28.6 \pm \\
3.6\end{array}$ & $\begin{array}{c}28.8 \pm \\
3.0\end{array}$ & $\begin{array}{c}28.9 \pm \\
3.7\end{array}$ & $\begin{array}{l}28.9 \\
\pm 2.7\end{array}$ & $\begin{array}{c}29.1 \pm \\
3.8\end{array}$ & $\begin{array}{c}30.4 \pm \\
3.5\end{array}$ \\
\hline $\begin{array}{c}\text { smoking } \\
1 \\
2 \\
3\end{array}$ & $\begin{array}{c}82 \\
19 \\
7\end{array}$ & $\begin{array}{c}30 \\
7 \\
1\end{array}$ & $\begin{array}{l}39 \\
5 \\
5\end{array}$ & $\begin{array}{c}21 \\
4 \\
1\end{array}$ & $\begin{array}{c}29 \\
4 \\
7\end{array}$ & $\begin{array}{c}13 \\
1 \\
1\end{array}$ & $\begin{array}{c}149 \\
46 \\
14\end{array}$ & $\begin{array}{c}80 \\
12 \\
1\end{array}$ \\
\hline $\begin{array}{l}\text { quetele } \\
\text { index }\end{array}$ & $\begin{array}{c}22.7 \pm \\
4.0\end{array}$ & $\begin{array}{c}22.6 \pm \\
3.9\end{array}$ & $\begin{array}{c}22.1 \pm \\
3.3\end{array}$ & $\begin{array}{c}22.5 \pm \\
3.7\end{array}$ & $\begin{array}{c}22.6 \pm \\
2.5\end{array}$ & $\begin{array}{l}22.6 \\
\pm 2.3\end{array}$ & $\begin{array}{c}22.4 \pm \\
3.2\end{array}$ & $\begin{array}{c}22.0 \pm \\
2.8\end{array}$ \\
\hline $\begin{array}{c}\text { child } \\
\text { number }\end{array}$ & $\begin{array}{c}1.5 \pm \\
0.6\end{array}$ & $\begin{array}{c}1.5 \pm \\
0.6\end{array}$ & $\begin{array}{l}1.5 \pm \\
0.5\end{array}$ & $\begin{array}{l}1.5 \pm \\
0.5\end{array}$ & $\begin{array}{c}1.7 \pm \\
0.6\end{array}$ & $\begin{array}{c}1.7 \pm \\
0.5\end{array}$ & $\begin{array}{l}1.6 \pm \\
0.6\end{array}$ & $\begin{array}{c}1.5 \pm \\
0.6\end{array}$ \\
\hline $\begin{array}{l}\text { breast- } \\
\text { feeding }\end{array}$ & $\begin{array}{l}5.4 \pm \\
13.3\end{array}$ & $\begin{array}{l}8.7 \pm \\
14.8\end{array}$ & $\begin{array}{l}7.1 \pm \\
14.0\end{array}$ & $\begin{array}{c}12.0 \pm \\
16.6\end{array}$ & $\begin{array}{c}5.4 \pm \\
9.7\end{array}$ & $\begin{array}{l}11.91 \\
\pm 2.9\end{array}$ & $\begin{array}{l}5.5 \pm \\
11.9\end{array}$ & $\begin{array}{c}11.5 \pm \\
16.8\end{array}$ \\
\hline fatperc & & $\begin{array}{c}3.0 \pm \\
0.6\end{array}$ & & $\begin{array}{c}3.2 \pm \\
0.7\end{array}$ & & $\begin{array}{c}2.8 \pm \\
0.8\end{array}$ & & $\begin{array}{c}3.0 \pm \\
0.8\end{array}$ \\
\hline $\begin{array}{l}\text { birth- } \\
\text { weight }\end{array}$ & $\begin{array}{c}3450 \pm \\
418\end{array}$ & $\begin{array}{c}3460 \pm \\
418\end{array}$ & $\begin{array}{c}3453 \pm \\
451\end{array}$ & $\begin{array}{c}3392 \pm \\
400\end{array}$ & $\begin{array}{c}3429 \pm \\
494\end{array}$ & $\begin{array}{r}3429 \\
\pm 494\end{array}$ & $\begin{array}{c}3564 \pm \\
442\end{array}$ & $\begin{array}{c}3627 \pm \\
460\end{array}$ \\
\hline
\end{tabular}

Smoking $1=$ non-smoking

Smoking $2=1-10$ cigarettes a day

Smoking $3=>10$ cigarettes a day.

Breast-feeding $=$ weeks of given breast-feeding to older children .

Fatperc $=$ fat percentage in human milk.

Blood = maternal plasma samples.

Milk = human milk samples. 


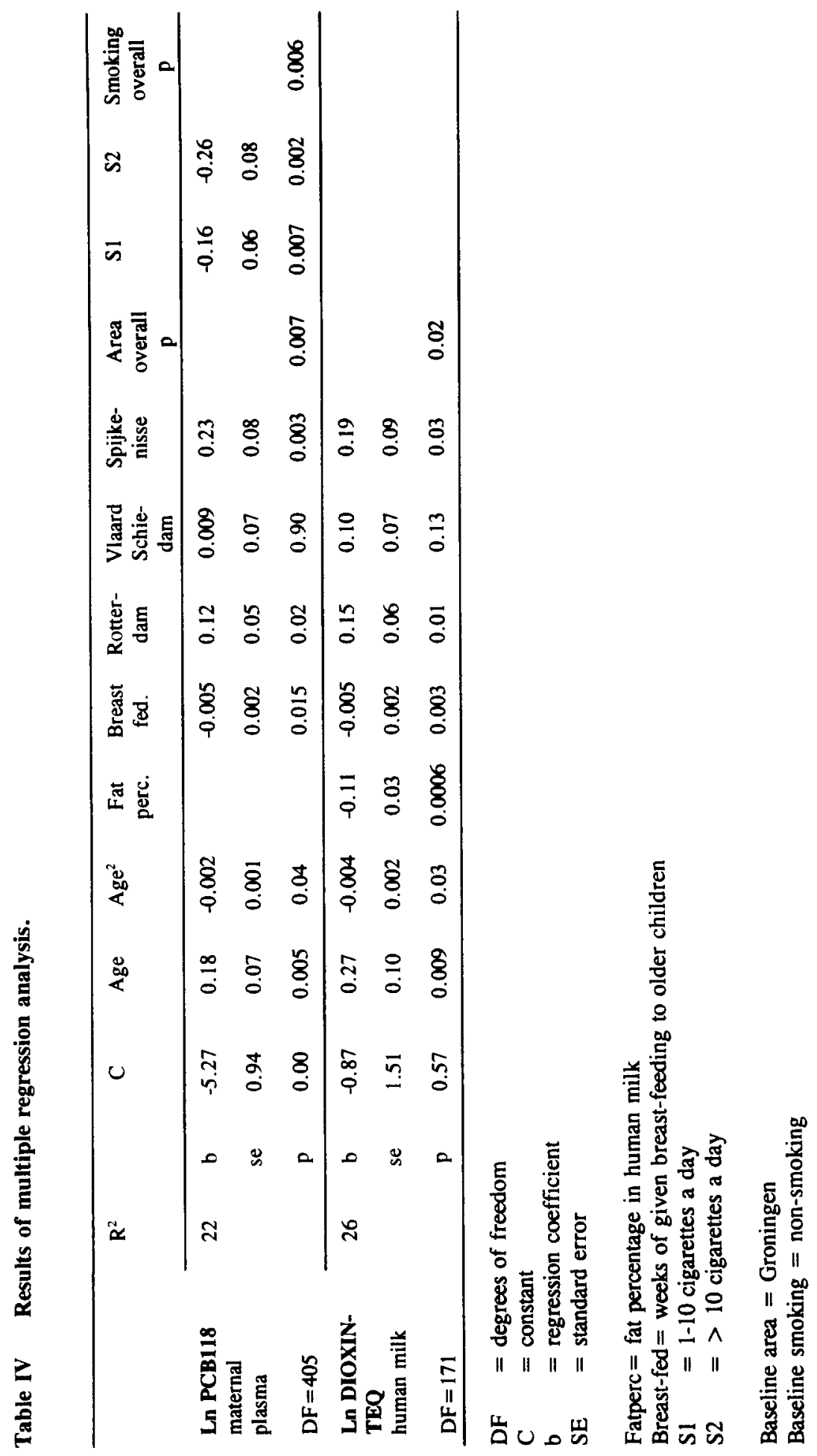




\section{Discussion}

We investigated PCB levels in plasma and PCB and dioxin levels in human milk of Dutch women living in highly industrialized, urban or more rural areas. After correction for covariates we found significantly higher levels of PCB 118 in maternal plasma, and of dioxin-TEQ and 10 individual dioxin and PCB congener levels in human milk from the western industrialized areas compared to the more rural areas in the northern part of the Netherlands.

It is well-known that dioxin and PCB levels in human milk can vary considerably in different countries. The WHO published data of a coordinated study in $1988^{10}$. The highest dioxin levels $(30-40 \mathrm{pg} \mathrm{TEQ} / \mathrm{g}$ fat) were found in Belgium, the Federal Republic of Germany, the Netherlands and the United Kingdom and these data are in agreement with our results; the lowest levels (10 pg TEQ/g fat) were measured in human milk samples from Hungaria and former Yugoslavia. Middle-range values were detected in samples from the USA, Canada, Japan, Austria, Poland and Scandinavia (15-24 pg TEQ/g fat). Some results from the WHO study indicate also that there are differences between the dioxin-TEQ level and specific dioxin congener levels in different geographic areas within one country. Such as is the case in the Hanoi area in Vietnam (low levels) compared to areas in southern Vietnam where the levels are elevated and this may be associated with the spraying of large amounts of Agent Orange, a herbicide contaminated with dioxins, during the war in the 1970s. In some countries (e.g. Austria, Belgium, Canada, Norway and Sweden) the levels are slightly but not significantly elevated in industrial and urban areas compared to rural areas. However, no such differences have been observed in former Yugoslavia or in human milk sampled in the Netherlands in 1988.

PCB results from the WHO study are not comparable for all participating countries because they used different analytical techniques. The mean sum of the measured PCB levels $(28,52,101,138,153$ and 180) in Western Europe was equally high $(392-762 \mathrm{ug} / \mathrm{kg}$ ) compared to the mean PCB sum of these same congeners in our study $(409 \mathrm{ug} / \mathrm{kg}$ ). The levels measured in Finland, the USA, Vietnam and Thailand were lower. Comparisons with the Scandinavian countries and former Yugoslavia were impossible because they used packed column rather than capillary column gas chromatography analysis. Results from different areas within one country, like Belgium, do not show significant differences between areas with different geographical, population or pollution profiles. In contrast to our study, PCB levels in the Netherlands reported in the WHO study, were slightly but not significantly elevated in rural compared to urban areas. In this study, significant differences in levels of several PCB and dioxin congeners were observed for women living in different areas in the Netherlands. It is possible that these congeners are emitted by some industries in close proximity to the living areas. In 1989 the milk of cows grazing close to a municipal solid waste incinerator, located in between Vlaardingen and Spijkenisse (a sampling area in this study), was excluded for human consumption because the dioxin level of $6 \mathrm{pg}$ I-TEQ/g milk fat was exceeded. ${ }^{3}$ Cows' milk in this area contained mainly higher chlorinated PCDDs and PCDFs. Near other incinerators lower as well as higher chlorinated PCDDs were found.

Waste incineration accounted in 1991 for approximately $85 \%$ of the total annual dioxin emission into the air in the Netherlands. ${ }^{2}$ Municipal waste incinerators are mainly located in the western part of the Netherlands. Besides incinerators there are other industries in the western area that produce dioxins as unwanted by-products. The 
consumption of dairy products, meat or fish (estimated as being $95 \%$ of the total human exposure ${ }^{9}$ ) from this area may be a source of elevated dioxin levels in human plasma and milk in this part of the Netherlands. However, in the Netherlands milk is transported throughout the whole country and consumption of milk products solely from the western industrialized area is unlikely.

Inhaling or dermal absorption of dioxins and PCBs is another route of exposure. However, it is estimated that less than $5 \%$ of the daily intake occurs via these routes. Since the combustion of leaded-petrol is also a source of dioxins ${ }^{18}$, living in densely populated areas with high vehicular traffic might be an additional source of exposure for humans. We conclude that the dioxin-TEQ level as well as some individual dioxin and PCB congener levels in women are significantly higher in the western industrialized area of the Netherlands compared to the northern more rural area. Further studies have to be carried out to determine the sources that account for these differences.

\section{References}

1. Rappe C, Andersson R, Bergqvist PA, Brohede C, Hansson M, Kjeller LO, et al. Overview of environmental fate of chlorinated dioxins and dibenzofurans, sources, levels and isomeric pattern in various matrices. Chemosphere 1987; 16: 1603-1618

2. Bremmer HJ, Troost LM, Kuipers G, De Koning J, Sein AA. Emissions of dioxins in the Netherlands. RIVM/TNO Report nr. 770501003 (summary in English) 1993.

3. Mocarelli P, Needham L, Marocchi A, Patterson GD, Brambilla P, Gerthoux PM, et al. Serum correlation of 2,3,7,8 tetrachlorodibenzo-p-dioxin and test results from selected residents of Seveso, Italy. J Toxicol Environ Health 1991; 32: 357

4. Wolfe WH, Michalek JE, Miner JC, Rahe AJ, Silva J, Thomas WF, et al.. Health status of Air Force veterans occupationally exposed to herbicides in Vietnam. 1. Physical health. J Am Med Assoc 1990; 264: 1824-1831

5. Liem AKD, Hoogerbrugge R, Kootstra PR, Van der Velde EG, De Jong APJM. Occurrence of dioxins in cow's milk in the vicinity of municipal waste incinerators and a metal reclamation plant in the Netherlands. Chemosphere 1990; 23: 1675-1684

6. De Voogt P, Brinkman UATh. Production, properties and usage of polychlorinated biphenyls. In: Kimbrough RD, Jensen AA (eds). Halogenated biphenyls, terphenyls, naphthalenes, dibenzodioxins and related products. Elsevier 1989; pp 3-45

7. Hara I. Health status and PCBs in blood of workers exposed to PCBs and of their children. Environ Health Perspect 1985; 59: 85-90

8. Kuratsune M, Yoshimura T, Matsuzaka J, Yamaguchi A. Epidemiological study on Yusho, a poisoning caused by ingestion of rice oil contaminated with a commercial brand of polychlorinated biphenyls. Environ Health Perspect 1972; 1: 119-128

9. Theelen RMC. Modeling of human exposure to TCDD and I-TEQ in the Netherlands: Background and occupational. In; Gallo MA, Scheuplein RJ, Van der Heijden KA (eds). Biological basis for risk assessment of dioxins and related compounds. Cold Spring Harbor Laboratory Press. Banbury report 1991; 
35: $277-290$

10. World Health Organisation. Levels of PCBs, PCDDs, and PCDFs in breast milk: results of WHO-coordinated interlaboratory quality control studies and analytical field studies. FADL, Copenhagen. Environmental Health Series, 1989; Vol 34

11. Touwen BCL, Huisjes HJ, Jurgens-v.d. Zee, Bierman-van Eendenburg MEC, Smrkovsky M, Olinga AA Obstetrical condition and neonatal neurological morbidity. An analysis with the help of the optimality concept. Early Hum Dev 1980; 4/3:207-228

12. Ballschmiter K, Bacher R, Mennel A, Fischer R, Riehle U, Swerev M. The determination of chlorinated biphenyls, chlorinated dibenzodioxins and chlorinated dibenzofurans by GC-MS. J High Resolut Chromatogr 1992; 15: 260-270

13. Burse VW, Korver MP, Needham LL, Lapeza CR, Boozer EL, Head SL, et al.. Gas chromatographic determination of polychlorinated biphenyls (as Aroclor 1254) in serum: Collaborative study. J Assoc Off Anal Chem 1989; 72: 649-659

14. Van Rhijn JA, Traag WA, Van de Spreng PG, Tuinstra LGMTh. Simultaneous determination of planar chlorobiphenyls and polychlorinated dibenzo-p-dioxins and -furans in Dutch milk using isotope dilution and gas chromatography-high-resolution mass spectrometry. J Chromatogr 1993; 630: 297-306

15. Tuinstra LGMTh, Van Rhijn JA, Traag WA, Van de Spreng P, Zuidema T, Horstman HJ. Method for the determination of dioxins, planar and other PCBs in human milk. In: Fiedler H, Frank H, Hutzinger O, Parzefall W, Riss A, Safe S (eds). Organohalogen Compounds 11, Analytical Methods, Formation and Sources. Federal Environmental Agency, Austria 1993; pp 181-183

16. NATO/CCMS. Pilot study on International Information Exchange on Dioxins and Related Compounds. International Toxicity Equivalency Factor (I-TEF). Method of Risk Assessment for Complex Mixtures of Dioxins and Related Compounds. Report number 176.

17. Ahlborg UG, Becking GC, Bimbaum LS, Brouwer A, Derks HJGM, Feeley M et al. Toxic Equivalency Factors for dioxin-like PCBs. Report on a WHO-ECEH and IPCS consultation, December 1993. Chemosphere 1994; 28:6.

18. Ballschmiter K, Buchert H, Niemczyk R, Munder A, Swerev M. Automobile exhausts versus municipal-waste incineration as sources of the polychloro-dibenzodioxins (PCDD) and -furans (PCDF) found in the environment. Chemosphere 1986; 15: 901-915 